\title{
INSCRIPCIONES Y ESCRITURAS ANDINAS: UN SISTEMA COMPLEJO Y DENSO DE VISUALIDADES, ORALIDADES Y ESPACIALIDADES
}

\author{
ANDEAN RECORDS AND WRITING: A COMPLEX, DENSE SYSTEM \\ OF VISUAL, ORAL AND SPATIAL ELEMENTS
}

\author{
Fernando Garcésa \& Walter Sánchez ${ }^{B}$
}

Hay evidencia de la existencia de distintos mecanismos de inscripción de la memoria y de la palabra en los Andes. La escritura consignada en cuero, papel y discos de arcilla, reportada desde la segunda mitad del siglo XIX, se consideraba un hecho del pasado. Gracias al acceso a colecciones y al trabajo etnográfico, hoy tenemos información importante sobre el modo de funcionamiento de los discos de arcilla en tanto realidad escrituraria compleja que se relaciona, además, con los cajones y retablos portátiles andinos. El artículo releva en los discos la existencia de diversos sistemas flexibles y multidimensionales que presentan elementos similares. A pesar de la gran diversidad del conjunto en cuanto a niveles y escalas, todos los sistemas se vinculan fuertemente con lo religioso y la ritualidad.

Palabras clave: inscripciones andinas, escritura andina, escritura logográfica, cajón andino, escritura y ritualidad.

Evidence has been found of Andean peoples employing different kinds of mechanisms to record events and ideas. Texts written on leather, paper and clay discs have been reported since the latter half of the $19^{\text {th }}$ century, but were considered to be artifacts of the past. Today, our increased access to ethnographic collections and works has provided important information about the role of clays discs in recording complex realities in written form, and their relation to Andean "cajones" (boxes) or portable altarpieces. This article examines these artifacts in order to highlight the existence of several flexible, multidimensional systems, identifying similarities among some of their elements. These systems have markedly different scopes and scales, but all are closely linked to the religious and ritual domains.

Keywords: Andean inscription, Andean writing, logographic writing, Andean box, writing and rituality.

\section{INTRODUCCIÓN}

El debate sobre los mecanismos de inscripción andina se ha centrado en la verificación de si hubo o no un sistema escriturario no alfabético previo a la conquista española. Ello ha llevado al estudio y análisis de objetos privilegiados de expresión comunicacional, tales como los khipus y los tocapus en qirus y textiles. Recientemente, se ha puesto atención sobre textos religiosos consignados en cuero, barro y papel desde la segunda mitad del siglo XIX, pero también en otros soportes, como son los cajones o pequeños retablos portátiles campesinos.

El artículo presenta las formas de inscripción andina como un hecho absolutamente presente (temporal y espacialmente), en el que se articulan de manera compleja y densa varios legados de origen prehispánico, colonial y republicano, así como visualidades, oralidades y espacialidades. Para ello mostramos avances investigativos a partir de los datos que nos ofrece la más importante colección de qillqalipichis, que reposa en el INIAM-UMSS, el estudio etnográfico de los rezos en discos de arcilla realizado en San Lucas (Chuquisaca-Bolivia) y avances de investigación sobre los cajones portátiles andinos, los que hasta hace poco se hallaban también asociados a fórmulas y "rezos" hechos con piedrecillas.

A Fernando Garcés, lingüista y pedagogo. Investigador del Instituto de Investigaciones Antropológicas y Museo de la Universidad Mayor de San Simón, Cochabamba, mail: ferumss@gmail.com

B Walter Sánchez, sociólogo y arqueólogo. Director del Instituto de Investigaciones Antropológicas y Museo de la Universidad Mayor de San Simón, Cochabamba, mail: walteryambae@hotmail.com 


\section{El debate sobre las escrituras prehispánicas no alfabéticas}

Existe un amplio debate sobre la existencia de algún tipo de escritura prehispánica en los Andes. En este sentido, el instrumento de memoria más estudiado ha sido el khipu (Urton 1998, Salomon 2004, Artzi 2008). De las investigaciones de las últimas décadas queda claro que aquel no solo era una herramienta para el uso contable sino también para el despliegue de narrativas varias.

Aparte de lo postulado por Gary Urton (1998) y los cuestionados documentos Miccinelli (Laurencich 2009), en general se acepta que los habitantes de los Andes no desarrollaron una escritura fonográfica, sea silábica o alfabética. ${ }^{1}$ Sin embargo, una serie de evidencias tanto cronísticas como visuales revelaría la existencia de distintos mecanismos de inscripción de la memoria y de la palabra.

Así, Sarmiento de Gamboa atribuye a Pachacuti Inga Yupanqui la construcción de una suerte de historia oficial sobre tablones pintados (Sarmiento de Gamboa [1572] 1942: 46-47, 94); Molina también afirma que en Poqen Cancha se encontraban pintadas en tablas la vida de cada uno de los incas (Molina 1575: ff. 1r.-1v.); Acosta dice que los indios suplían la falta de escritura, para llevar la cuenta de las cuestiones de gobierno, en pinturas y khipus (Acosta 2002 [1590]: 385). Guamán Poma (1615: fol. 203), por su parte, muestra cómo el Inca hablaba con las huacas representadas en una suerte de maqueta circular.

Otro espacio de producción sígnica importante fueron los tocapu, tanto en textiles como en qiru. Los trabajos de De Rojas (2008) y de Silverman (2012) muestran la manera en que los tocapus textiles inscribían elementos narrativos, sea de linajes familiares y de heráldica o de historias locales. Lo propio puede decirse de las narrativas históricas (Ziólkowski et al. 2008) o productivas (Silverman 2007) expresadas en qirus.

\section{Los qillqalipichis y los discos de arcilla: hechos del presente}

Desde el siglo xix tenemos una relativa abundante información que da cuenta de la existencia de una escritura logográfica en los Andes plasmada en cuero y papel (Posnansky 1945: 118-120; Ibarra 1953, 1967: 475-491; Garcés y Sánchez 2014). ${ }^{2}$ Lo mismo puede decirse de los discos, tortas, pizzas o llutasqas. Se tiene noticias de ellos desde por lo menos mediados del siglo pasado (Ibarra 1953). En la zona quechua del sur del país, se siguen usando las llut'asqas para rezar durante la Cuaresma y la Semana Santa.

Algunas características de estos rezos son:

- Aunque pareciera que se trata de una expresión de sometimiento colonial a la imposición de la Iglesia católica, los rezos son algo mucho más complejo: expresan una suerte de religiosidad apropiada que se inscribe en la lógica andina del pago y del cumplimiento (Ferraro 2004).

- Expresan tanto oraciones como aspectos de la doctrina; es decir, no se ciñen a la funcionalidad que les da la Iglesia católica. Así, el credo, por ejemplo, es un elemento de la doctrina que se recita durante la misa; en los lugares donde se practican los rezos andinos, se rezan/cantan/gritan durante Cuaresma y Semana Santa, y para curarse de una determinada enfermedad o para alejar el mal de la familia (Sánchez \& Sanzetenea 2000).

- Uno de los recursos lingüísticos más usados es el rebus: la evocación de un concepto a través de un sonido similar (Garcés \& Sánchez 2014).

- La direccionalidad de la escritura era múltiple; es decir, se podían leer los textos de manera horizontal, vertical y circular (Ibarra 1953). Hasta mediados del siglo pasado, la forma privilegiada era la escritura en boustrophedon, es decir, mediante la redacción alternativa de izquierda a derecha y de derecha a izquierda de cada renglón (Ibarra 1953). ${ }^{3}$ Hoy, por lo menos en el área quechua de San Lucas, se practica de manera exclusiva la forma circular. ${ }^{4}$

- El soporte principal en el que se elaboran los rezos, hoy en día, es el disco de arcilla. Los cueros ya no se usan (figs. 1 y 2).

Las tortas actuales (fig. 3) miden entre 20 y $50 \mathrm{~cm}$ (pero pueden llegar a ser mucho más grandes, según afirman los "maestros doctrineros"). ${ }^{5}$ Los materiales que intervienen en la elaboración del rezo son: arcilla, lanas, palos, ramas, papel, hierbas, flores, vidrios, semillas, telas, piedras, plumas, espinos, etc. (Garcés 2014).

La secuencia del rezo se realiza con un palo tomado de la mano del maestro; esta va conectando las figuras de la "torta" con la vocalización o el canto del rezo, separando el mismo en unidades segmentadas. Cada una de esas unidades se encuentra representada en el disco de arcilla. Se van señalando las partes correspondientes con un "palito" que sirve de regulación rítmica para que el maestro/a haga repetir a los demás participantes. En 


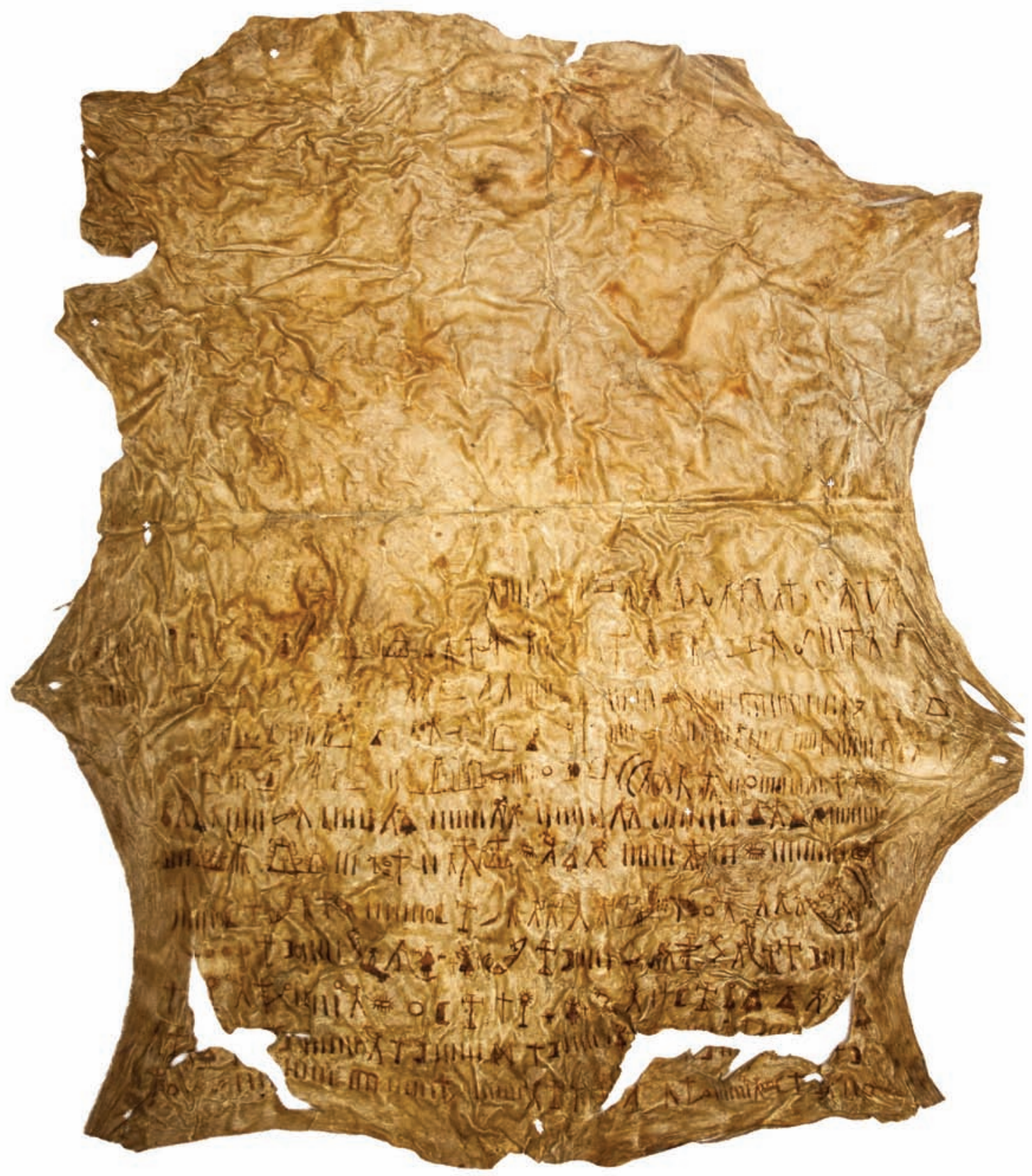

Figura 1. Detalle de rezo en cuero. Colección iniam-umss. Código 1357 (fotografía de Archivo iniam-umss). Figure 1. Detail of prayer recorded on leather. INIAM-UMSS Collection. Code 1357 (photo by INIAM-UMSS Archive).

otros casos (fig. 4), los rezos se cantan, separando sus partes con una suerte de glissando entre cada unidad (Garcés 2014). ${ }^{6}$

Los maestros doctrineros son nombrados por las comunidades para este cargo por el periodo de un año. Las tortas se realizan durante el periodo de Cuaresma, mientras que el ciclo de aprendizaje de los rezos va desde el momento de elaboración hasta cuando se rompen o deshacen, el jueves o viernes de Semana Santa. Aunque la vinculación de los rezos con las tortas se da especialmente en Cuaresma o Semana Santa, en las familias se practican los rezos en una suerte de calendarización relacionada con eventos climáticos o con actividades sociofamiliares (Sánchez \& Sanzetenea 2000; Garcés 2014). 


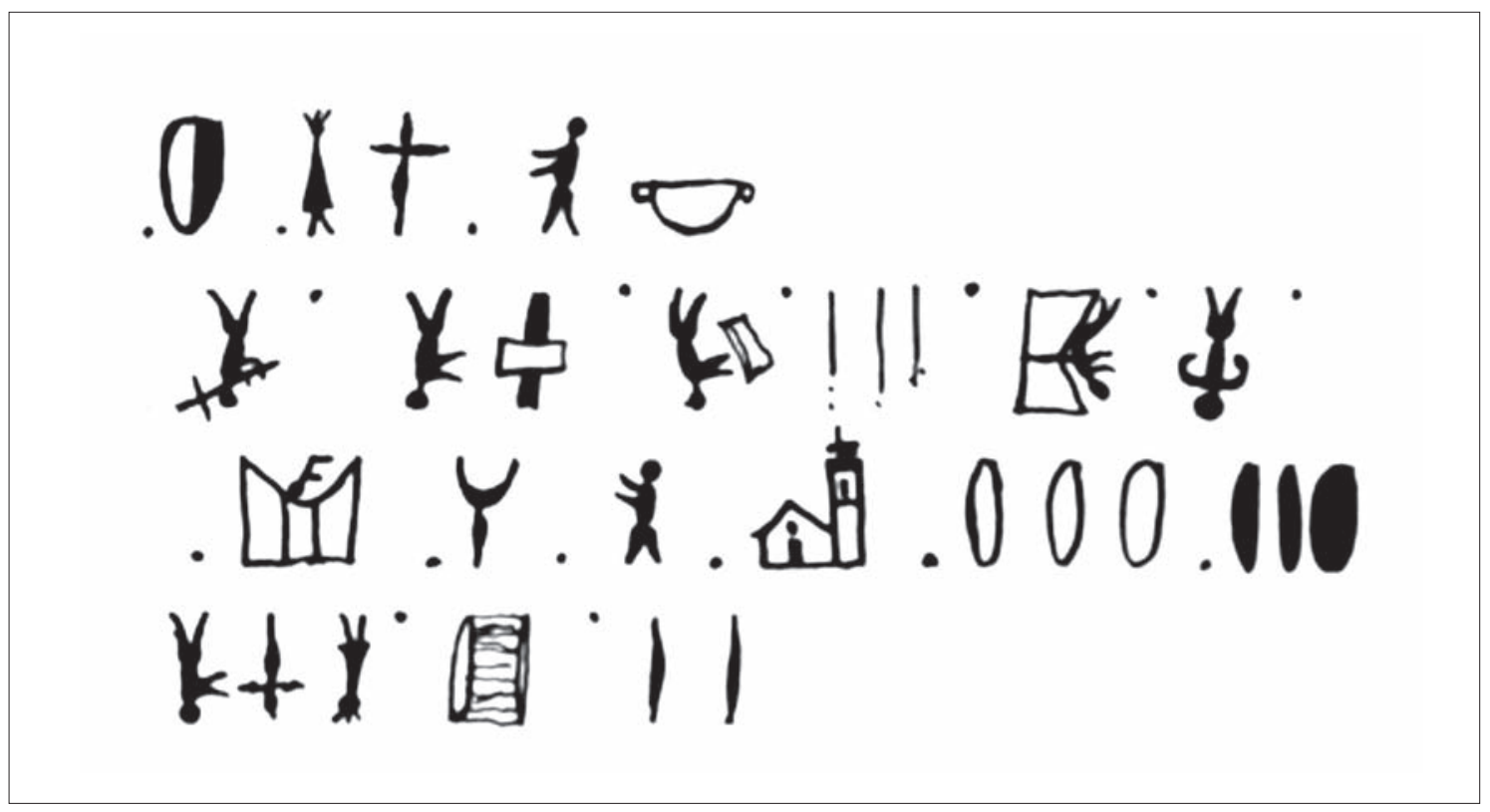

Figura 2. Rezo Jesús Lazariño en papel. Colección InIAM-Umss. Código eIA-P-037 (InIAM-Umss 2014: 93). Figure 2. Jesús Lazariño prayer on paper. INIAM-UMSS collection. Code EIA-P-037 (INIAM-UMSS 2014: 93).

Espacialmente, las tortas y los rezos se realizan en lugares marginales de la oficialidad eclesial.7 Así, por ejemplo, en Padcoyo se hacen en la capilla antigua; en Ocurí y en el mismo Padcoyo, al fondo de la capilla; por último, en Tirahoyo se llevan a cabo en otro ambiente, separado de la iglesia principal. ${ }^{8}$ En cuanto a la articulación entre esta práctica comunal y la Iglesia católica local, se trata de mundos semiparalelos. La Iglesia oficial sabe de su existencia y de alguna manera estas expresiones religiosas están vinculadas a, pero no gobernadas o controladas por ella.

Las tortas y los rezos forman parte de un sistema mayor de articulación entre oralidad, visualidad, motricidad, sonoridad y memoria, inscrito en los debates sobre formas escriturarias logográficas (Szemiñski 2010) encontradas en tejidos (Arnold 2012), qirus (Ziólkowski et al. 2008) y en los propios textos alfabéticos coloniales (Garcés \& Sánchez 2014). ${ }^{9}$

Por otra parte, aun cuando se trata de un mecanismo exitoso de preservación de la memoria que prácticamente reproduce lo consignado en la doctrina del Tercer Concilio Limense (1584), en varios casos encontramos transformaciones lingüísticas profundas. Así, en el rezo Mamanchik Santa Inlesya, elaborado por Santos Condori en la Semana Santa de 2014, el recurso de memoria de lo que los especialistas llaman rebus

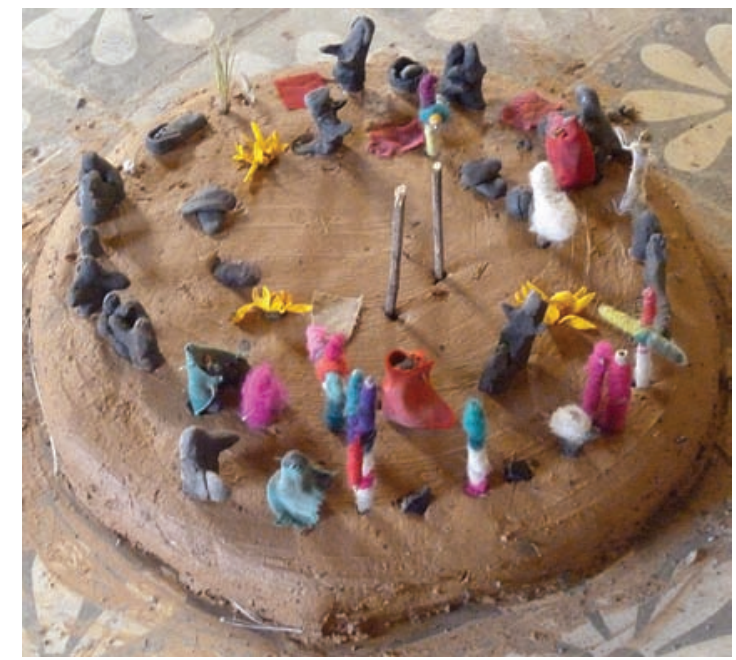

Figura 3. Rezo Napaykuyki María, elaborado por Isidoro Flores. Padcoyo, 2015 (fotografía de Fernando Garcés). Figure 3. Napaykuyki María prayer, created by Isidoro Flores. Padcoyo, 2015 (photo by Fernando Garcés).

(la evocación de un concepto a través de un sonido similar) ha terminado fosilizándose en una suerte de fórmula religiosa en la que ya no tiene importancia el significado específico de cada palabra sino el contexto total del rezo. La performance quechua es referencial de cara al significado específico del rezo, razón por la que, 


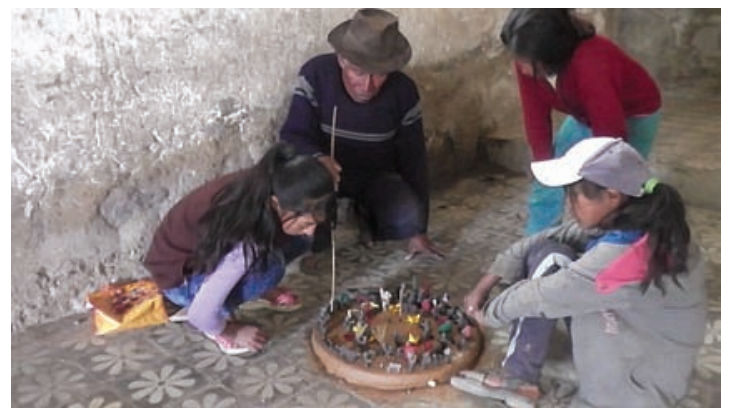

Figura 4. Isidoro Flores (2015) enseñando uno de los rezos a niños de Padcoyo (fotografía de Fernando Garcés). Figure 4. Isidoro Flores (2015) teaching one of the prayers to children in Padcoyo (photo by Fernando Garcés).

reconsiderada, se trata de una suerte de enunciación mítica fosilizada que, sin embargo, solo tiene sentido en el contexto de emisión (Arnold \& Yapita 2007: 353393). Por ejemplo, la palabra sacramento se construye a partir de una figura con andrajos (saksa) y una figura de mujer que representa a "Carmen"; así, la vocalización de este segmento del rezo será saksakaran. La idea de matrimonio se elabora con una figura humana seguida de una bandera (un pedazo de papel) que se "bate"; su vocalización será waterminu (Garcés 2014) (fig. 5).

Una pregunta importante que se hacen los estudiosos de estos materiales es si se pueden considerar los rezos andinos una auténtica escritura. Los editores del Catecismo de Huntington (Mitchel \& Jaye 1996; Jaye \& Mitchel 1999) insisten en que este tipo de rezos con escritura logográfica alude a mecanismos mnemónicos que no reproducen sonidos. Así, serían "a mnemonic aid rather than phonetic writing" (Jaye \& Mitchel 1999: 5); más adelante, señalan que: "Unfortunately, careful analysis reveals that the pictographic catechisms are also mnemonic aids rather than phonetic writing" (Jaye \& Mitchel 1999: 9). El argumento fundamental se basa en que la escritura obedece a principios decodificadores universales y no idiosincráticos, mientras que estos materiales servirían para recordar textos específicos, razón por la que varían considerablemente de un lugar a otro y por la que sería imposible descifrar los signos si no describieran textos estandarizados bien conocidos. Se trata de signos mnemónicos que ayudan a las personas a recordar textos conocidos por la tradición oral (Jaye \& Mitchel 1999: 9). En la misma línea, Szemiñski (2010: 142) afirma que esta escritura no sirve para anotar y conservar nueva información, sino solo para recordar textos aprendidos por todos, textos aprendidos durante la catequesis básica.

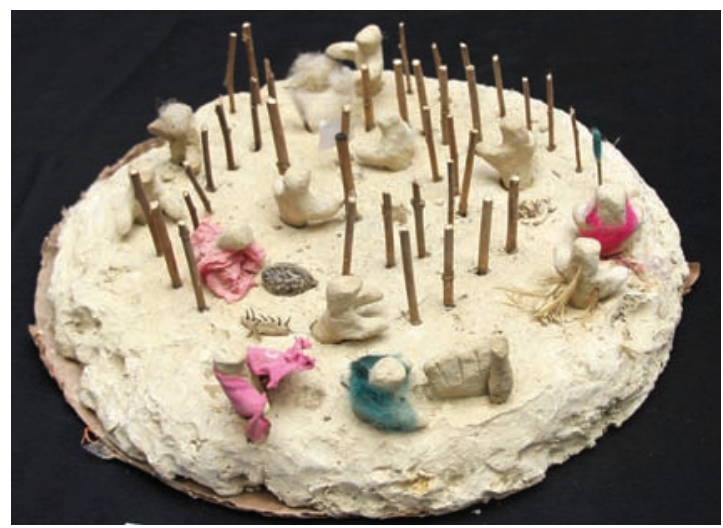

Figura 5. Rezo Mamanchik Santa Inlesya, elaborado por Santos Condori. Ocurí, 2014 (fotografía de Marco Bustamante). Figure 5. Mamanchik Santa Inlesya prayer, created by Santos Condori. Ocurí, 2014 (photo by Marco Bustamante).

Esto no es lo que vio Dick Ibarra en la década del cuarenta del siglo pasado. Él afirma que en San Lucas "fue fácil encontrar a los indígenas escritores, los cuales no tuvieron inconveniente alguno en leer y escribir en nuestra presencia, incluso textos que ellos no conocían y para los cuales les fue preciso inventar signos especiales" (Ibarra 1953: 13). En la comunidad de Yapusiri, cercana a San Lucas, aún hoy se recuerda a Julián Herrera, anciano fallecido hace pocos años, quien escribía todo con "dibujos", ya que no conocía la "escritura con letras".

Lo curioso es que, según estudios varios, la escritura alfabética también se lee logográficamente. Mariño, por ejemplo, nos recuerda que

Cuando tenemos una duda ortográfica, para resolverla, lo que hacemos es escribir la palabra y mirarla; si su silueta no nos 'choca', entonces está correctamente escrita. Esa es una sencilla y contundente prueba de que nosotros leemos ideográficamente, es decir, no leemos sílaba por sílaba sino el contorno de la palabra total, como lo hacen los chinos. De ninguna otra forma sería posible leer a alta velocidad (1988: 365).

El otro aspecto fundamental es la conjetura sobre el origen prehispánico de esta escritura logográfica. Tomemos nuevamente como punto de partida el Catecismo Huntington. Los editores ubican su texto, tomando en cuenta el papel, la caligrafía de los títulos y los detalles de la vestimenta en las pictografías, hacia fines del siglo XIX (Jaye \& Mitchel 1999: 6-7). Desde esta perspectiva, los "rezos" son evidencia de un origen poscolonial y arraigados en la iconografía europea. 
Jaye y Mitchel (1999) opinan que los varios sistemas mnemónicos usados como registro - tal es el caso de los khipus- habrían sido tan eficientes que disuadieron a los grupos prehispánicos andinos de desarrollar una escritura fonética. La convicción de los investigadores de los siglos xx y xxi de que los habitantes de los Andes centrales no conocían la escritura antes de la conquista española habría sido el factor determinante de su desidia en el estudio de otras formas de anotación y preservación de la información (Szemiñski 2010). Como insinuábamos al inicio de este artículo, el khipu se constituyó en, prácticamente, el único material que recibió la atención de los españoles del siglo XVI.

De tal forma que, con respecto a una posible escritura prehispánica en los Andes, las dos tendencias se proponen así:

\footnotetext{
Los que opinan que en Tawantin Suyu no existía la escritura tienen mucha razón al indicar la ausencia de transcripciones conservadas hasta nuestros tiempos. / Los partidarios de una escritura andina opinan que tales inscripciones se conservan en forma de signos en tejidos y en qirus. Los signos rectangulares complicados y abstractos se llaman t’uqapu (Szemiñski 2010: 131-132).
}

Por los antecedentes prehispánicos ofrecidos y por la conexión con la vida agrícola y familiar, es muy probable que la escritura logográfica que aún hoy se emplea en el altiplano y los valles bolivianos tenga origen prehispánico y preincaico. Como ya decía Ibarra Grasso en 1953, habría sido un recurso no usado por las élites sino por indígenas del "común" para temas religiosos, y por esa razón se habría articulado fácilmente con el sistema expresivo católico; curiosamente, este sería también el motivo por el que no se le ha prestado la debida atención. Se trata, como ya señalamos, de una escritura vigente, aunque funciona de manera semiclandestina, escondida de antropólogos y lingüistas.

Dos aspectos merecen destacarse de lo expuesto: 1) Hasta ahora, hemos trabajado sobre tales materiales como hechos del pasado, no como hechos expresivos vigentes. Desde esta perspectiva, lo importante ha sido descubrir qué tan antiguos son estos materiales y cuánta continuidad con expresiones religiosas precatólicas manifiestan (Ibarra 1953; Hartmann 1989; Jaye \& Michel 1999; Szemiñski 2010).

2) Por ello mismo, salvo excepciones (Arnold \& Yapita 2007), nos hemos preocupado por encontrar los significados específicos de los mensajes, sobre todo tratando de dilucidar, como ya se dijo, las huellas del pasado prehispánico.

Por otro lado, cabe resaltar cierta indiferencia con la que se ha abordado este tema y estas prácticas, tal vez por tratarse de expresiones religiosas que reproducen la doctrina católica del siglo XVI.

En este sentido, lo que nos muestra San Lucas:

- Es una práctica absolutamente vigente que se despliega en un tiempo específico (el tiempo de "doctrina", según el calendario católico; el inicio del chiaki tiempo, según el calendario andino), vinculado a espacios rituales comunales y, por tanto, "locales".

- Los rezos en discos de arcilla encuentran significación en el conjunto de la performance ritual, más que ser mecanismos expresivos palabra a palabra (Arnold \& Yapita 2007: 353-393); es decir, funcionan como unas especies de fórmulas conjurales inscritas en la lógica del pago.

- Recrean formas andinas de lectura sígnica, tales como el sentido circular de las mesas rituales (Fernández 1995) y el boustrophedon que, en este caso, expresa la lógica textil de una trama que entrelaza urdimbres de sentido (Arnold \& Espejo 2013).

- Nos ayudan a repensar nuestras concepciones en torno a lo colonial. Aunque pareciera tratarse de un sistema de subordinación a la memoria de dominación colonial y al poder adoctrinador de la iglesia, realmente son expresiones de una accionalidad inscrita en la activación de diferenciales de poder dentro de los márgenes que históricamente han configurado la Iglesia y el Estado.

- Los rezos andinos se inscriben en lo que parece ser una distribución especializada de mensajes plasmada en textiles, qiru y una variedad de soportes para la expresión religiosa (piedra, madera, cuero y arcilla). Así, Arnold afirma que los textiles podían ser leídos como repositorio documental sobre el ámbito tributario (2012); los qiru parecen narrar historias oficiales incaicas (Ziólkowski et al. 2008); las varas de Tupicocha funcionan como escritura sin palabras para organizar las relaciones sociales de la comunidad y el Estado (Salomon 2004) y los rezos, como hemos visto, reproducen temas explícitamente religiosos.

- En tal sentido, una aproximación a esta forma escrituraria requiere entradas de diferente índole, que tienen que ver con campos relacionales como la lingüística y la teoría de la escritura, la semiótica, las teorías del 
poder, el sistema religioso y político, la temporalidad y la espacialidad andina, por citar algunas.

\section{El cajón portátil andino y su asociación con piedrecillas para rezos}

En un texto escrito en 1953, Ibarra Grasso describe, a partir del relato de un campesino, lo siguiente:

[O]btuvimos datos sobre una nueva forma de escribir que existiría en las provincias del Norte del Departamento de Potosí, y que consistiría en el uso de piedrecillas de diversos colores y formas; uno de nuestros informantes nos dijo que hacía muchos años un hermano suyo, sacerdote, había sido designado para un pueblecillo indígena de la Provincia Chayanta, y que él lo había acompañado a su destino. Al entrar en la iglesia se encontraron con que había varias cajitas de madera que contenían colecciones de piedrecitas de distintos colores y formas, las cuales no sabían qué eran y el Sacristán, un indígena del lugar, les dijo que eran rezos; como no lo creían hizo venir a una india que sabía leerlos y ésta dispuso las piedrecitas en líneas sobre el suelo y leyó en cada una de ellas una palabra de los rezos más comunes (1953: 17).

Dos hechos resaltan en este relato: (1) la presencia de varias "cajitas de madera" y (2) dentro de ellas, "colecciones de piedrecitas". Es posible que las "cajitas" fueran pequeños retablos portátiles, denominados desde la Colonia como "cajones", y que los campesinos de Bolivia conservan en sus casas o dejan en las iglesias. Las "piedrecitas de distintos colores y formas" son explícitamente señalados como "rezos".

Lamentablemente, Ibarra Grasso al no haberlos visto sino solo accedido a un relato, no puede dar mayor información ni sobre las cajitas ni sobre qué tipo de rezos eran. Es posible, sin embargo, que estos pequeños retablos portátiles contuvieran en su interior imágenes ya sea de santos, vírgenes y/o "cristos". Es factible también que las distintas "colecciones" de rezos se vincularan con las deidades contenidas en el interior de las cajitas.

Si bien hasta la actualidad las distintas colecciones custodiadas y conservadas en repositorios de Bolivia y de otros países (Cf. Ibarra 1953; Sánchez \& Sanzetenea 2000; INIAM-MUSS 2014) muestran una mayoritaria presencia de rezos asociados a los santos sacramentos, la doctrina y los rituales católicos, la existencia de estas colecciones de rezos asociados a cajitas depositadas, sin duda, por los campesinos puede estar dando cuenta de la presencia de rezos dedicados explícitamente a una gran diversidad de deidades "cristianas" que forman parte de un panteón religioso local. Es posible suponer, entonces, que eventualmente fueron usadas siguiendo un calendario agrícola-ganadero anual.

Los retablos portátiles fueron introducidos por la Iglesia colonial desde la segunda mitad del siglo xvI. A pesar de las prohibiciones de la Iglesia colonial para que los indígenas realizaran imágenes cristianas, en el siglo XVII existían "sacerdotes" indígenas que recorrían los Andes cargando sus cajones portátiles. Tal el caso de Diego Layme, quien hacia 1681 caminaba por los valles de Cochabamba con dos cajones: el de la Virgen de Copacabana y Santiago y el de un "Cristo cruz". Todos estos artefactos portátiles eran puestos sobre una mesa a modo de altar y, durante el ritual nocturno, el chamán convocaba al "espíritu santo", el que aparecía en forma de paloma y acudía batiendo sus alas para responder las preguntas de los campesinos (Sánchez 2015).

Es posible que Diego Layme, "natural de Copacabana", no solo haya recorrido comunidades cargando sus cajones y formando "hermandades" y "cofradías", sino que también haya portado sus rezos en algún tipo de soporte, entre ellos, piedrecillas. De hecho, el uso de estas piedrecillas dentro de los espacios sagrados cristianos era tan importante en el primer tercio del siglo xvir que José de Acosta señala, con cierto aire de asombro: "y es cosa de ver á viejos ya caducos con una rueda hecha de pedrezuelas aprender el Padre nuestro, y con otra el Ave María, y con otra el Credo, y saber qual piedra es" (Acosta 2002 [1590]: 386). Si tomamos en cuenta que solo eran confeccionados por "viejos ya caducos", es posible que el uso de estos pequeños artefactos culturales se orientara, anteriormente, a recordar fórmulas y rezos dedicados a los wak'a locales.

Acosta pone en evidencia otra cuestión: que cada rezo cristiano tenía una propia "rueda" de piedrillas. Este dato muestra que los campesinos estaban en condiciones de componer rezos no solo para aquellos oficios importantes desde el punto de vista de la Iglesia, sino para sus propias wak'a: para otros santos, vírgenes, y "cristos" incorporados dentro de su sistema ritual-religioso.

De hecho, el chamán Diego Layme muestra que para la segunda mitad del siglo XVII, vírgenes y santos, resignificados, formaban parte ya de su cosmología religiosa. No obstante, de acuerdo con las fuentes documentales, formaban parte de la parafernalia usada por los especialistas. Es posible que, fruto de todo el proceso de persecución y de extirpación de idolatrías, estas deidades ubicadas en pequeños cajones hayan sido incorporadas 
por los campesinos a su panteón religioso, pero dentro de un ámbito domiciliario. Este hecho permitió, para el caso de la sierra peruana, que "(e)l dueño de un retablo podía celebrar actos cúlticos sin temor alguno. No resulta extraño por eso que figure con frecuencia en las mesas de los wamanis andinos; y que motive festividades que se apartan sensiblemente de los patrones ortodoxos" (Macera 2009 [1981]: 178). Tal hecho tuvo, sin duda, un fin no solo religioso, sino político: "estos retablos debilitaron el poder central de la Iglesia" (Macera 2009 [1981]: 178).

La consolidación del retablo como un artefacto religioso fuera del control eclesiástico, en tanto objeto domiciliario, tenía antecedentes previos. Así, Francisco de Ávila se quejaba de los ídolos que los indios tenían en sus casas:

He hallado tantos Idolos, tan regalados y uenerados en las casas de los Indios que yo tenía por Christianos, que ni se pueden contar ni dezir, y que estando en la plaça el templo dedicado al uerdadero Dios se le ofrece el Sacro Sacrificio de la Missa están alrededor dél en diferentes barrios Cediculas, Sacellos o Delubros, que son unas casillas, templos lúgubres y obscuros de cada uno, con su Idolo; Sacerdotes y seruicio para su falso culto, y esto en todo el pueblo y entre todos los conuecinos es público; porque en cualquiera ay lo propio, $y$ solo el cura no lo sabe, ni a abido quien se lo aya dicho en tantos años, y con estos confesaban cada año, y muchos comulgaban, y así no hallo que aya ni uno que no aya apostado y sea formalísisimo Herege, y los niños se iban criando a este modo (Ávila ¿1648?, citado en Duviols 2003: 56-57).

Arriaga, por su parte, señala que antes de la llegada de los conquistadores hispanos, y aún durante la Colonia, los campesinos tenían

Conopas, q en Cuzco, y por alla arriva llaman Chancas; son propriamente sus dioses Lares, y Penates y assi las llaman tambien Huacicamayoc, el mayordomo, o dueño de casa, esta son de diversas materias, y figuras, aunque de notable, o en la color, o en la figura [...]. / Pero lo ordinario es, que las Conopas se hereden siempre de padres a hijos, y es cosa cierta y averiguada en todos los pueblos de esta visita, que entre los hermanos, el mayor tiene siempre la Conopa de sus Padres [...]. Estas conopas es cosa cierta, que las tenían todos en tiempo de su gentilidad antes de la venida de los Españoles, y la misma certidumbre ay de que las tiene ahora los nietos de aquellos, pues sus padres las heredaron, de los suyos, y no las echaron ellos por ay, antes las an guardado como la cosa más preciosa, que sus padres les dejavan, ni tan poco se las an quitado hasta esta visita (1621: 14-15).

Si bien las conopa prehispánicas tenían figuras de animales importantes dentro de la economía campesina, así como de productos agrícolas (mama zara, etc.), muy pronto aparecen conopa que representan a los animales introducidos como vacas, toros, ovejas, mulas y burros. Todos estos animales-conopa son vinculados principalmente a santos cristianos, generándose nuevos reensamblajes que dan cuenta de los cambios que los nuevos contextos relacionales coloniales habían creado. Así, Santiago aparece asociado no solo al culto a los cerros -como elemento fecundante y fecundador de las parcelas agrícolas y propiciadoras de lluvias-, sino a un animal de altura: la llama; San Isidro Labrador, a la producción agrícola y a la protección de las yuntas para arar; San Juan Bautista, al ganado ovejuno. En todos estos casos, los animales-conopa reaparecen, junto al santo, dentro de las pequeñas cajitas portátiles.

No resulta extraño que durante el siglo xviII se consolide, en todos los Andes, un nuevo calendario ritual-religioso agrícola-ganadero anual en el que se integran santos, vírgenes y "cristos" con conopas/deidades andinas. El pequeño retablo portátil domiciliario (conteniendo pequeñas imágenes tridimensionales), resignificado en su función de "mayordomo o dueño de casa", será un artefacto cultural y cultual importante no solo para la reproducción económica familiar, sino una suerte de protector de cada miembro de una familia durante los viajes interecológicos y en el trabajo dentro de las minas; además, será una suerte de $w a k^{\prime} a$ para el pedido de lluvias, la reproducción de animales, la defensa ante enfermedades, el cuidado de la casa, etc.

Aunque su calendario en gran medida quedará articulado con el calendario de fiestas y festividades locales y regionales, tendrá, por sus características familiares, su propia dinámica domiciliaria. No obstante,

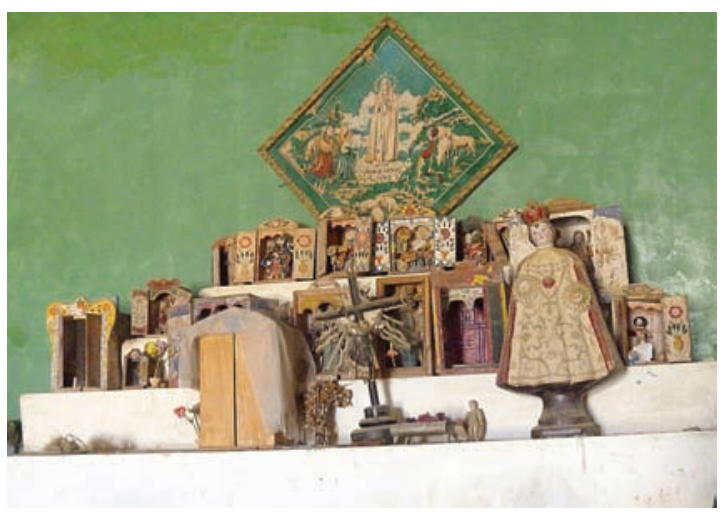

Figura 6. Cajones en capilla de Ocurí, San Lucas, 2014 (fotografía de Soledad Guzmán). Figure 6. Andean altarpiece "boxes" at Ocurí Chapel, San Lucas, 2014 (photo by Soledad Guzmán). 


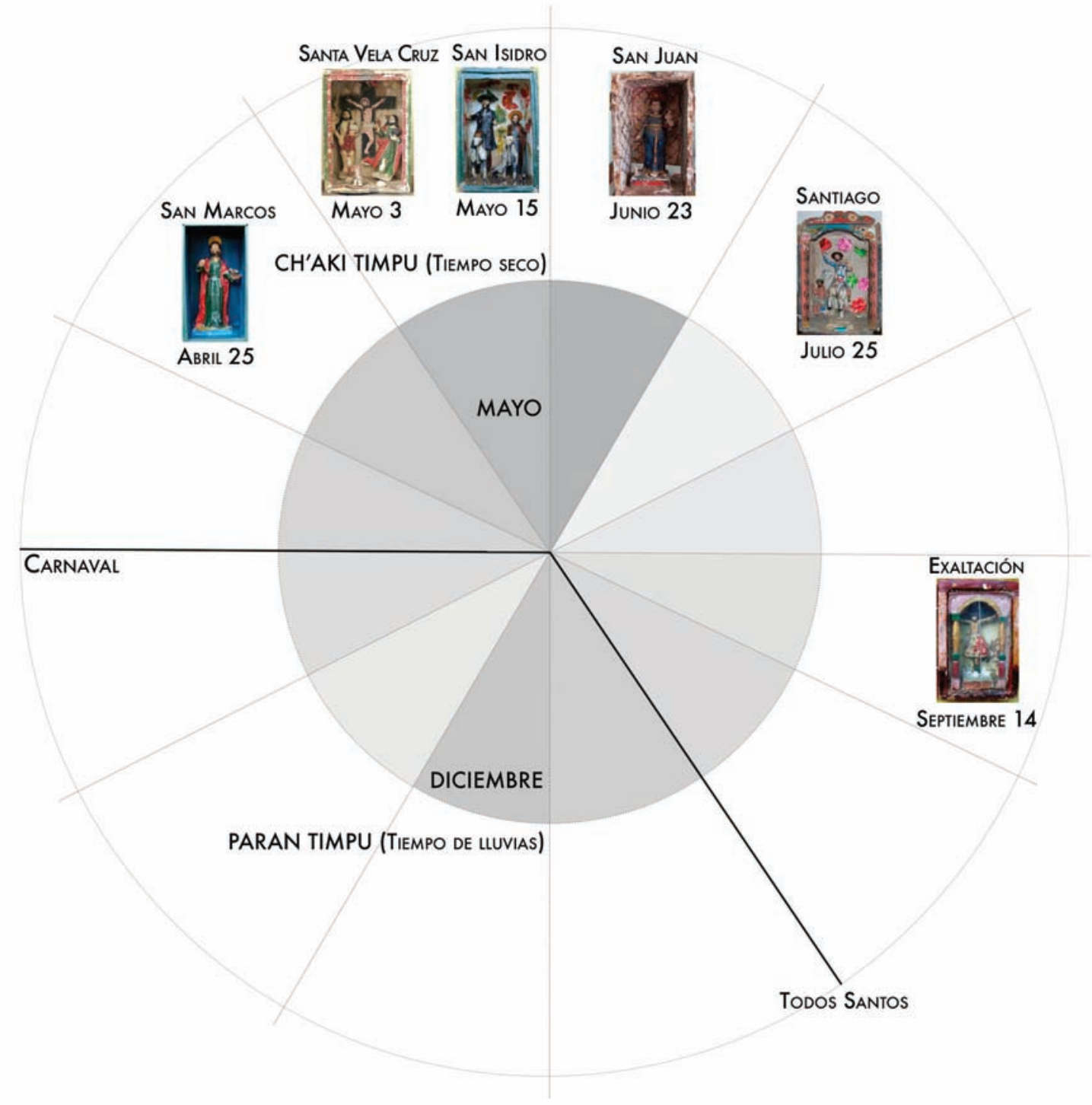

Figura 7. Calendario de cajones andinos según calendario climatológica anual (elaboración de Walter Sánchez). Figure 7. Calendar of Andean altarpiece boxes in order of the seasons (created by Walter Sánchez).

de tal autonomía privada, cajones y retablos portátiles serán llevados el día de su "fiesta" a la iglesia para que "oigan misa"; muchas veces serán depositados allí por varios años. En la sierra peruana serán parte importante de "mesas" rituales vinculadas a los Wamani (Arguedas 1976; Macera 2009 [1981]) y otros eventos (herraje de animales, por ejemplo). Luego, durante todo el resto del año, permanecerán como en quietud; aquellos cajones con puertas serán cerrados y guardados, hasta el momento en el que se necesite nuevamente la mediación de la deidad en cuestión (figs. 6 y 7).

Hay que tomar en cuenta que si bien la mayor parte de los cajones son monotemáticos, es decir, contienen un santo o una virgen asociado a una actividad (agrícola o ganadera) -de ahí que en muchas zonas los cajones hayan incluso tenido un nombre propio: cajón San Marcos, cajón San Lucas, cajón San Isidro, Santa Vera Cruz, Santiago, etc.-, existen otros multitemáticos; es decir, cajones que poseen hasta cuatro santos en bulto, por lo que su adscripción será a varios momentos festivos y rituales y con propósitos múltiples, aunque siempre existe una deidad principal que da la identidad al cajón (figs. 8 y 9).

Es posible que los discos de arcilla provenientes de Oruro, repletos de piedrecillas de diversa forma y colores, retazos de cerámica con marcas geométricas 


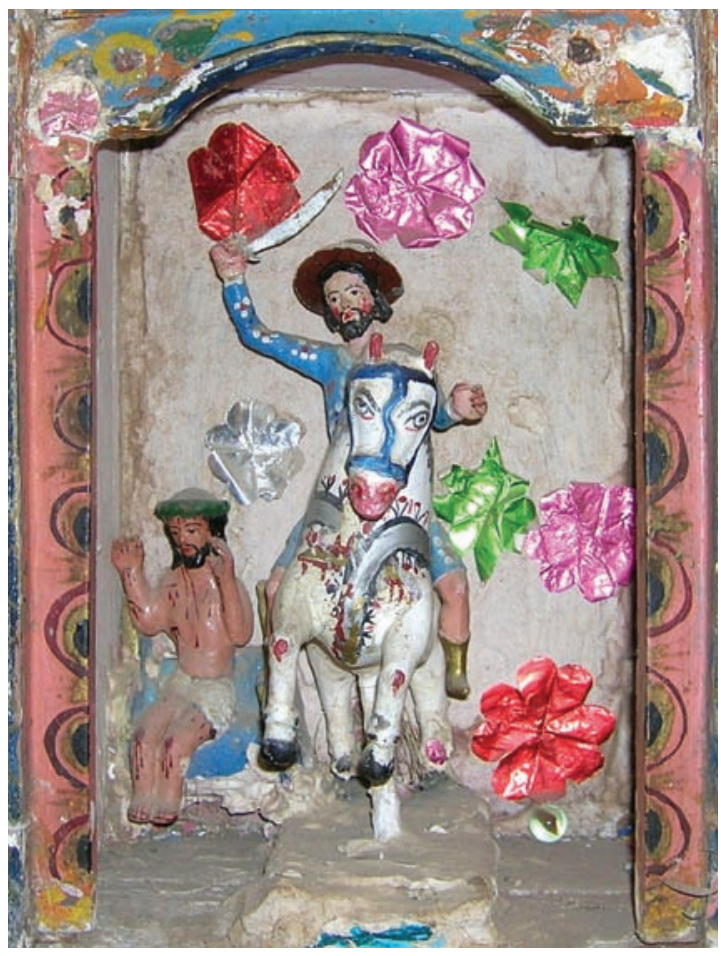

Figura 8. Cajón monotemático con Tata Santiago. Colección privada (fotografía de Walter Sánchez). Figure 8. Monothematic altarpiece box with "Tata Santiago" (St. James). Private collection (photo by Walter Sánchez).

(círculos, líneas rectas, cruces, etc.) y que se hallan en los museos de Oruro y de Cochabamba sean elementos supervivientes de rezos asociados a los retablos campesinos y hechos para ser usados durante sus festividades. Es posible también que, en muchas zonas, cada cajón -sea monotemático o multitemático- haya portado dentro de sí su propio rezo, tal como lo señala Ibarra Grasso. Si tal hipótesis es cierta, entonces, es posible que tal sistema de "escritura" haya estado fuera del control de la Iglesia e incluso del "maestro doctrinero" local, ya que pudo tener una propia inscripción y ordenamiento familiar. Dicho de otra manera, al contrario de los discos de arcilla (y también de aquellos rezos hechos en cuero y papel) conservados hasta la actualidad y que reproducen lo señalado y enseñado desde la doctrina del Tercer Concilio Limense (1584), por lo general de aplicación comunal, estos "rezos" locales, asociados a deidades locales puestas en los cajones, pudieron haber tenido fórmulas rituales-religiosas propias, creadas y conocidas solo por los propietarios de los cajones, quienes tenían la libertad de crear sus propios signos especiales. Además, dado

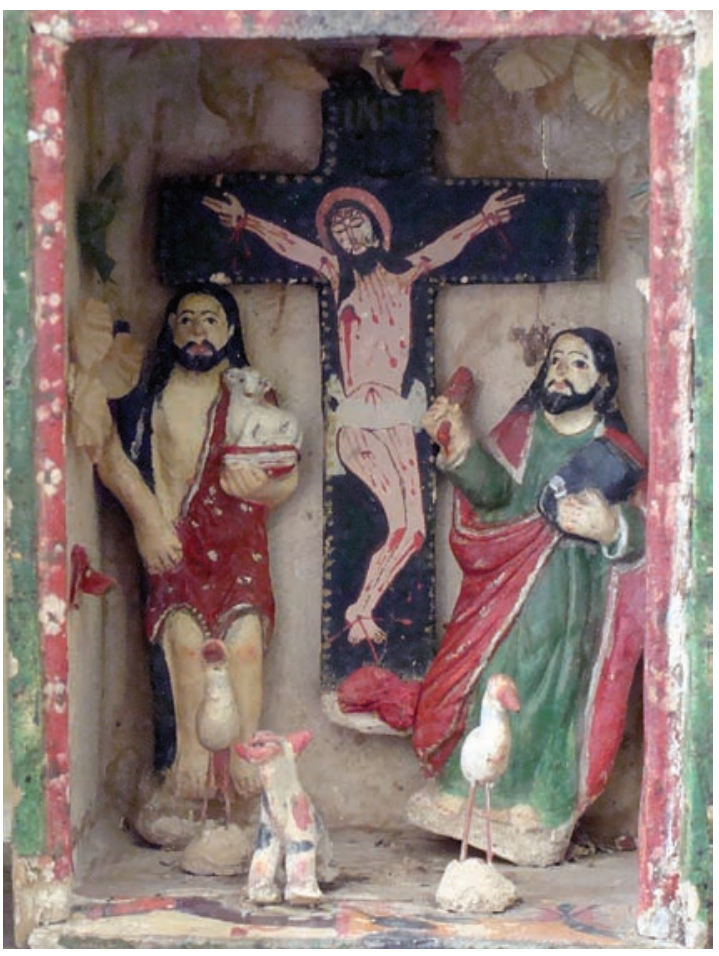

Figura 9. Cajón multitemático con Santa Vera Cruz, San Juan Bautista y San Marcos. Colección privada (fotografía de Walter Sánchez). Figure 9. Multi-thematic altarpiece box with "Saint of the True Cross", St. John the Baptist and Saint Mark. Private collection (photo by Walter Sánchez).

que funcionaban en momentos y situaciones concretas y específicas, podían ser recordados y "leídos" fácilmente por los miembros de una familia (figs. 10 y 11).

Desde tal perspectiva, toma cuerpo lo señalado por Ibarra Grasso: que este tipo de "escritura" habría sido una técnica usada por la gente común. De ser así, posiblemente se mantenga como una práctica escrituraria vigente en muchas comunidades, pero por su carácter domiciliario y privado, escondida de la mirada exterior.

\section{La inscripción y la escritura andina: un sistema complejo, presente y denso}

\section{¿Cómo pensamos el problema?}

Abandonamos la concepción lingüística de escritura, entendida como escritura alfabética, como un sistema autónomo y superior a otras formas escriturarias. Planteamos entonces asumir una noción semiótica de la escritura. Desde esta perspectiva, la pregunta no es si los habitantes de los Andes cultivaron o no escritura, sino 


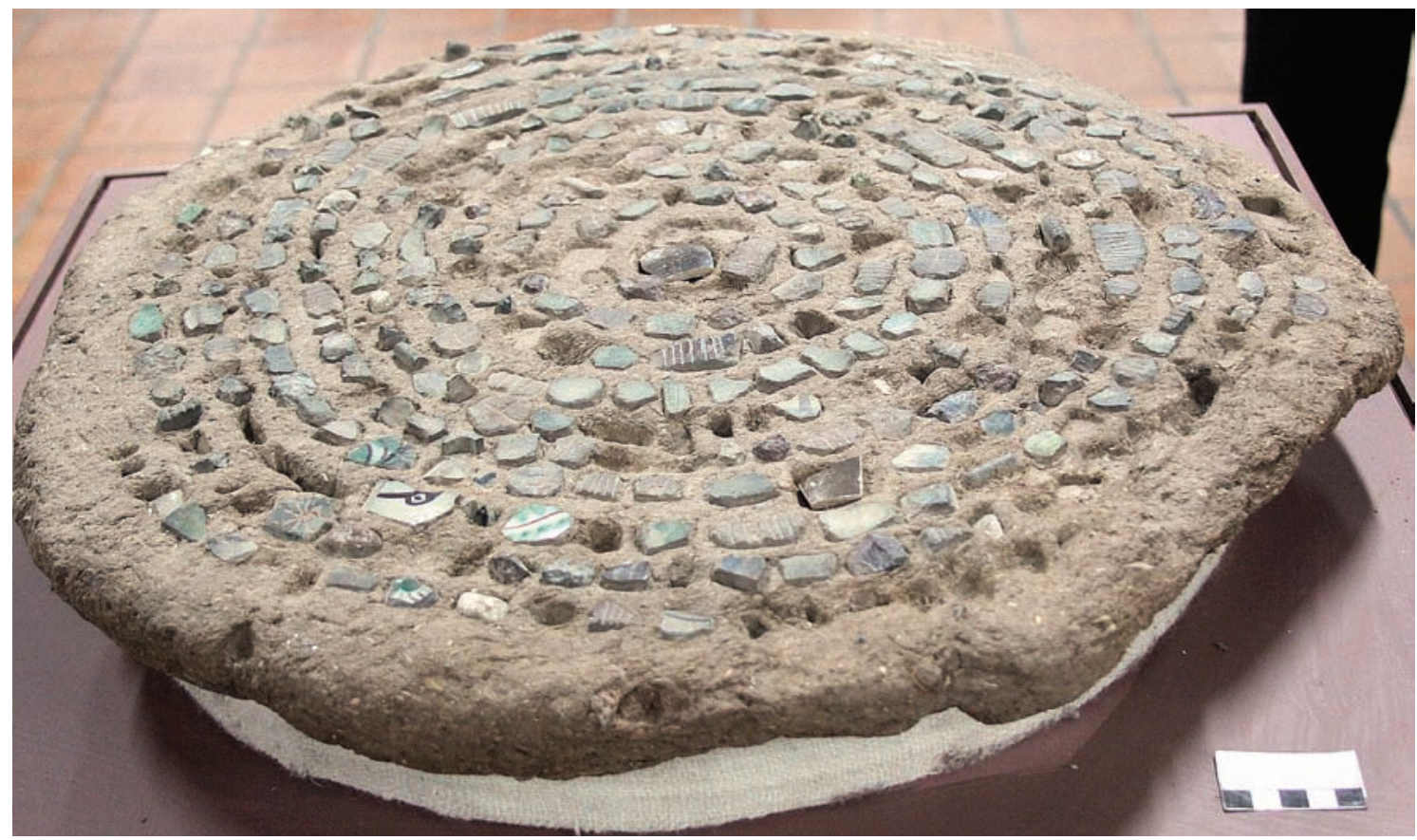

Figura 10. Disco de barro. Museo Nacional Antropológico "Eduardo López Rivas”. Oruro. Vitrina AM-D-2421-63 (fotografía de Marco Bustamante). Figure 10. Clay disc. Museo Nacional Antropológico "Eduardo López Rivas”. Oruro. Window display AM-D-2421-63 (photo by Marco Bustamante).

de qué forma inscribían el mundo de sus significados y significaciones. El temor de contestar esta pregunta es el de arrastrarnos a un campo sumamente amplio y complejo marcado por diferentes soportes, subsistemas y ámbitos específicos, en el que se alojan los subsistemas, canales expresivos, etc. Esta complejidad articula enmarañadamente pasado y presente, bidimensionalidad y tridimensionalidad, macrosoportes (paisaje, por ejemplo) y microsoportes (papel o textil), representaciones discursivas y adopciones tecnológicas, etc.

Recurrimos a las crónicas como evidencia histórica de que hubo algún tipo de inscripción de la memoria, pero nos parece raro no encontrar -y luchamos por hacerlo- evidencias materiales de tal presencia. Nos interesamos por los qillqalipichis con el fin de constatar un tipo peculiar de escritura, aunque sea religiosa -lo que ya nos lleva a dudar de su "autenticidad"-, que nos puede ayudar a suplir la ausencia material prehispánica. Nos interesamos por el uso actual de discos de arcilla y cajones religiosos como muestras de sistemas expresivos complejos en su significación.

En cualquier caso, el debate y nuestras investigaciones y preocupaciones por la escritura andina son siempre presentes y bajo la marca de nuestros intereses:

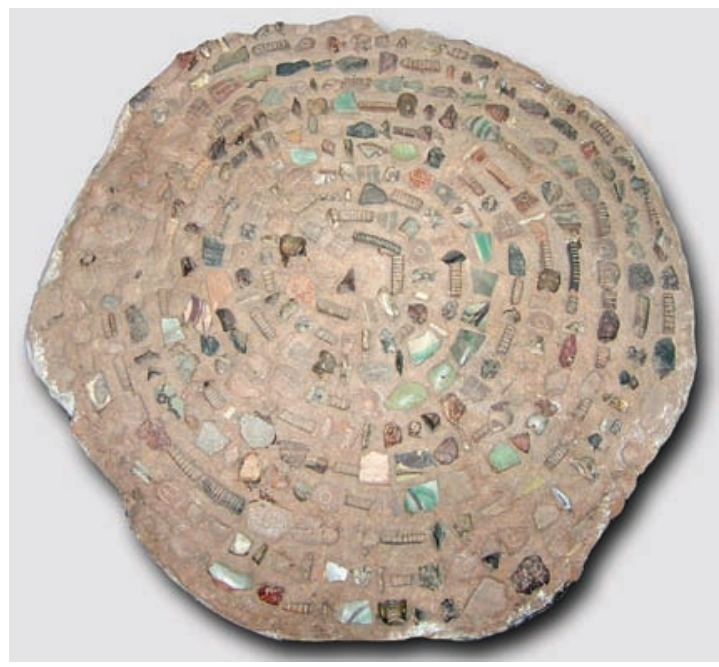

Figura 11. Disco de barro procedente de Puqui, Oruro. Colección INIAM-UMSS (fotografía de Archivo INIAM-UMSS). Figure 11. Clay disc from Puqui, Oruro. INIAM-UMSS collection (photo by INIAMuMss Archive).

políticos, pedagógicos, sociales, filantrópicos o cualquier otro. Desde este punto de vista, se trata de comprender nuestros propios sentidos representacionales con la presencia de los "escritores" andinos. 
Pensar la escritura andina desde su densidad y complejidad implica acercarnos a ella en la perspectiva de las relaciones de poder que entran en juego: las de los poderes estatales y religiosos que la han configurado, pero también la de los escritores que se han movido en el campo de sus posibilidades de significación no solo explicitando conocimientos y significados sino además ocultando y burlando, trocando y mezclando, simulando y extrapolando. De manera que la inscripcionalidad andina se muestra como un campo de significaciones abiertas que lucha contra la captura racional dominante.

\section{¿Cuál es el debate? Producción de sentidos prehispánicos}

El debate sobre la existencia o no de escritura en los Andes es un falso debate que no ha permitido avanzar en la comprensión de los sistemas de producción de sentidos inscritos en distintos soportes: piedra, barro, madera, textiles, paisajes, arte rupestre y el cuerpo (tatuajes, pinturas faciales, etc.). Se busca un sistema común, homogeneizador, cuando hay que advertir la existencia de diversos sistemas flexibles y multidimensionales particulares, con elementos de similitud.

Estas inscripciones funcionaron y funcionan a distinto nivel. Destacan por su gran diversidad y por no constituir un sistema cerrado; por el contrario, es abierto. Así, hay sistemas que funcionan a nivel macro, estatal, y otros a nivel panregional, regional, local, familiar e incluso individual. Tienen igualmente distintas funcionalidades: burocráticas (khipus, varas), históricas (tablas), rituales (estatuillas, dibujos, cajones), marcadores espaciales (apachetas), etc.

Son especialmente importantes aquellas inscripciones vinculadas al mundo religioso. La ritualidad es en sí misma un sistema de producción de sentido para el que se utiliza una gran cantidad de artefactos culturales: estatuillas, inscripciones en vasijas, textiles, etc., que mediatizan sistemas de sentidos particulares, según los contextos en los que son usados. Es el contexto el que da coherencia a la producción de sentido; fuera del contexto (temporal-espacial: pacha), pierden su significancia.

¿Cómo cambian estos sistemas de producción de sentidos y cómo son vehiculados?

La presencia hispana introduce nuevas formas de producción de sentidos: burocráticos, sociales, espaciales, rituales y religiosos. Dos formas son principales: (1) la escritura alfabética, ligada a la religión cristiana docta, la burocracia y la producción de la historia y (2) la escritura visual, relacionada con la pintura, la escultura, la arquitectura, la construcción de un nuevo paisaje sacro y el reordenamiento territorial. Todos estos cambios movilizan a la gente y las comunidades que recrean y resignifican sus sistemas de producción de sentidos. La ritualidad como inscripción densa se mantiene como forma distinta de producción de sentidos frente a la escritura hispana (alfabética y visual).

¿Cuál es la lógica de ordenamiento de estos sistemas de inscripción y producción de sentidos?

Estos sistemas deben ser entendidos dentro del calendario ritual anual. En el calendario anual se integran varios calendarios: (a) religioso (estatal, panregional, regional, comunal, familiar e individual); (b) climatológico (jallu pacha, awti pacha; paran timpu o ch'aki timpu); (c) productivo (agrícola-pecuario), ritual, musical, de instrumentos musicales, de rezos, de santos y vírgenes. Estos calendarios están organizados espacialmente y se vinculan a $w a k^{\prime} a$, cerros, etc. Estos tienen una vinculación con lo cristiano. El ritual, dentro del calendario temporal-espacial, es lo que moviliza la emergencia de los distintos soportes. En ese momento se produce el ensamblaje de todos los elementos dispersos: se conjugan, se complementan. Los agentes humanos desde distintas partes despliegan inscripciones y sistemas escriturarios en diversos niveles: desde individuales hasta sociales. Tiempo-espacio, paisajes, deidades, sujetos, objetos, sonidos, colores y olores conjuncionan.

Fuera del ritual, son sistemas de inscripción "sin vida”. No funcionan. Están inertes. Se los guarda o se los desecha (se cierran los cajones, se destruyen las tortas de barro, se guardan los textiles). Los objetos tienen agency en el ritual, tienen "vida"; fuera del ritual, no.

La escritura alfabética es importante en lo cotidiano, en la vida profana; los sistemas de inscripción no alfabéticos, en los momentos del ritual. En tal sentido, todos estos soportes no pueden ser entendidos de manera separada sino que en su unidad densa. Es un sistema que funciona a partir de la aglutinación y el ensamblaje de múltiples sistemas escriturarios: visuales, olorosos, alfabéticos, no alfabéticos, musicales, sonoros, paisajísticos, etc. 


\section{NOTAS}

${ }^{1}$ Un análisis crítico de los documentos Miccinelli puede encontrarse en Albó (1998). Acerca de la distinción entre escrituras logográficas y fonográficas, véase Gelb (1963).

${ }^{2}$ El Instituto de Investigaciones Antropológicas y Museo de la Universidad Mayor de San Simón posee una de las colecciones más importantes qillqalipichis en cuero y papel (INIAM-UMSS 2014).

${ }^{3}$ Esta escritura en boustrophedon, aunque también conocida en otras inscripciones arcaicas, especialmente griegas, en el caso de los Andes reproducía la direccionalidad textil de la faz de urdimbre (Arnold \& Espejo 2013: 194).

${ }^{4} \mathrm{La}$ forma circular de elaboración de los rezos y de su lectura se relaciona con la forma circular en que se elaboran las mesas rituales aimaras a fin de cerrar el convite para que "ningún indeseable se introduzca en el círculo de invitados" y "para garantizar su hermetismo y cierre respecto al exterior” (Fernández 1995: 266).

${ }^{5}$ Especialmente, cuando se refieren al rezo churuwillas, cuyo disco -señalan- puede llegar a medir más de un metro de diámetro.

${ }^{6}$ En el ámbito musical, el glissando es un efecto sonoro que consiste en pasar de un sonido a otro más agudo o más grave haciendo que se escuchen todos los intermedios posibles.

${ }^{7}$ Se trata de una marginalidad desde la Iglesia católica; desde los propios comunarios podríamos pensar en "otra centralidad" fuera de la oficialidad católica.

${ }^{8}$ En el caso de Vitichi, la maestra y las "luterneras" (rezadoras), cantan los rezos fuera de la capilla, en su muro exterior y de pie (ACLO 2010).

${ }^{9}$ Un detalle importante es la vinculación entre la emisión verbal del rezo y una actividad motriz específica; además de lo visto con el caso particular de las "tortas", tenemos el testimonio de Carlos Noya, quien relata cómo, en 1964, entre los Chipayas se rezaba tocando un khipu a manera de rosario (comunicación personal, 21/03/12). Lo propio puede decirse de la manera como la maestra de Vitichi dirige los rezos: puskhando [hilando] (ACLO 2010).

\section{REFERENCIAS}

Aclo, 2010. Fiesta de Pascua. Municipio de Vitichi. 56 min. Producciones Aclo, Bolivia.

AcostA, J., 2002 [1590]. Historia natural o moral de las Indias. Madrid: Dastin.

Albó, X., 1998. La nueva crónica y buen gobierno: ¿Obra de Guamán Poma o de jesuitas? Anthropologica 16: 307-348.

Arguedas, J.M., 1976. Del retablo mágico al retablo mercantil. En Señores e indios. Acerca de la cultura quechua, A. Rama, Comp., pp. 248-254. Buenos Aires: Arca.

Arnold, D., 2012. El textil y la documentación del tributo en los Andes: Los significados del tejido en contextos tributarios. Lima: Fondo Editorial de la Asamblea Nacional de Rectores.

Arnold, D. \& E. Espejo, 2013. El textil tridimensional. La naturaleza del tejido como objeto y como sujeto. La Paz: ILCA.

Arnold, D. \& J. D. Yapita, 2000. El rincón de las cabezas. Luchas textuales, educación y tierras en los Andes. La Paz: UMSA-ILCA.

Arnold, D. \& J. D. YApita, 2007. Hilos sueltos: Los andes desde el textil. La Paz: Plural.

ArRiaga, P., 1621. Extirpacion de la idolatría del Pirv. Lima: Geronymo de Contreras Impressor de Libros.
Artzi, B., 2008. El secreto del nudo del khipu. Iberoamerica Global 2: 34-46. Israel: The Hebrew University of Jerusalem.

De Rojas, D., 2008. Los tokapu. Graficación de la emblemática Inka. La Paz: CIMA.

Duviols, P., 2003. Procesos y visitas de idolatrías. Cajatambo, siglo XVII. Lima: Pontificia Universidad Católica del Perú-Instituto Francés de Estudios Andinos.

FernándeZ, G., 1995. El banquete aymara. Mesas y yatiris. La Paz: HISBOL. Ferraro, E., 2004. Reciprocidad, don y deuda. Quito: FLAcso-Abya Yala

GARCÉs, F., 2014. Aprender otra(s) escritura(s) en los Andes: Una invitación a repensar la pedagogía desde la etnografía. Arqueoantropológicas 4: 113-160.

GARCÉs, F. \& W. SÁNCHEZ, 2014. La colección de escrituras ideográficas andinas del Instituto de Investigaciones Antropológicas y Museo de la Universidad Mayor de San Simón: una forma de narrar sin letras. En Escritura andina: Pictografía e ideografía en cuero y papel, pp. 13-37. Cochabamba: INIAM-UMss.

GeLb, I., 1963 [1952]. A study of writing. Chicago: The University of Chicago Press.

Guamán Poma de Ayala, F., 1615. El primer nueva Coronica y Buen Gobierno. The Guaman Poma Website [online] $<$ http://www.kb.dk/permalink/2006/poma/info/en/frontpage. htm > [Citado 15-02-13].

Hartmann, R., 1989. Pictografías de tipo religioso-cristiano del área andina-Dos ejemplos. En Iglesia, religión y sociedad en la historia latinoamericana, 1492-1945, tomo II, A. Anderle, Ed., pp. 169-188. Szeged: Universidad József Attila.

IbARrA, D., 1953. La escritura indígena andina. La Paz: Alcaldía Municipal de La Paz.

IBARRA, D., 1967. Argentina indígena y prehistoria americana. Buenos Aires: TEA.

INIAM-UMSS, 2014. Escritura andina: pictografía e ideografía en cuero y papel. Cochabamba: INIAM-UMSS.

Jaye, B. \& W. Mitchel, 1999. Introduction. En Picturing faith. A Facsimile edition of the pictographic quechua catechism in the Huntington Free Library, B. Jaye \& W. Mitchel, Ed., pp. 5-13. Bronx: Huntington Free Library.

Laurencich, L., 2009. Presentación de los documentos Miccinelli. En Exsul Immeritus Blas Valera Populo Suo e Historia et Rudimenta Linguae Piruanorum. Nativos, jesuitas y españoles en dos documentos secretos del siglo XVII, L. Laurencich, Ed., pp. 17-85. Chachapoyas: Municipalidad de Chachapoyas.

MACERA, P., 2009 [1981]. Trincheras y fronteras del arte popular peruano. Ensayos de Pablo Macera, M. Pinto, Comp. Lima: Fondo Editorial del Congreso del Perú.

MARIÑo, G., 1988. Escritos sobre escritura. Bogotá: Dimensión Educativa.

Mitchel, W. \& B. Jaye, 1996. Pictographs in the Andes: The Huntington Free Library Quechua Catechism. Latin Amerian Indian. Literatures Journal 12 (1): 1-42.

Molina, C. 1575. Relación de las fabvlas i ritos de los Ingas hecha por Christoual de molina cura de la perroquia de N. Sa de los Remedios de el Hospital de los Naturales de la ciudad de el Cuzco dirigida al reuerendissimo Señor Obispo don Sebastian de el Artaum del consejo de su Mag[esta]d. Biblioteca Nacional de Madrid. Ms. 3169.

Pachacuti Yamqui Salcamaygua, J., 1993 [c. 1613]. Relacion de antigüedades deste reyno del Piru. Lima-Cuzco: Instituto Francés de Estudios Andinos-Centro Bartolomé de las Casas.

Posnansky, A., 1945. Tihuanacu. Cuna del Hombre Americano, tomo III. La Paz: Ministerio de Educación. 
SAlomon, F., 2004. The cord keepers. Khipus and Cultural Life in a Peruvian Village. Durham-London: Duke University Press.

SÁNCHEZ, W., 2016. Capac Eterno. Idolatrías y producción de sentido desde Chirusi-Cochabamba. InIAM-Umss. (En prensa).

SÁNCheZ, W. \& R. SANZETEnEA, 2000. Rogativas andinas. Ideografías andinas. Boletín del INIAN-MUSEO 8. Cochabamba: Instituto de Investigaciones Antropológicas-Museo Arqueológico.

Sarmiento de Gamboa, P., 1942 [1572]. Historia de los Incas. Buenos Aires: Emecé.

Silverman, G., 2007. Los tocapus incas como escritura pictórica. Lectura de un vaso ceremonial inca. En Sublevando el Virreinato. Documentos contestatarios a la historiografía tradicional del Perú Colonial, L. Laurencich \& P. Numhauser, Eds., pp. 443-467. Quito: Abya Yala.

Silverman, G., 2012. The signs of Empire Inka Writing. Cuzco: Kopygraf.
SZEMiÑski, J., 2010. ¿Qué sabemos de qillqa en QullaSuyu? Estudios Latinoamericanos 30: 129-186. Polonia: Sociedad Polaca de Estudios Latinoamericamos.

Tercer Concilio Limense, 1584. Doctrina christiana y catecismo para la instrvccion de los indios, y de las demás personas, que han de ser enseñadas en nuestra sancta Fé. Lima: Antonio Ricardo Impressor.

URTon, G., 1998. From knots to narratives: Reconstructing the art of historial record keeping in the Andes from spanish transcription of Inca khipus. Ethnohistory 45 (3): 409-438. American Society for Ethnohistory.

Zıólkowski, M.; J. Arabas \& J. SZemiñski, 2008. La historia de los Querus: Apuntes acerca de la relación entre las representaciones figurativas y los signos tocapus. En Lenguajes visuales de los incas, P. González \& T. Bray, Eds., pp. 163-176. Oxford: British Archeaological Reports. 